\title{
The role of pro-inflammatory S100A9 in Alzheimer's disease amyloid-neuroinflammatory cascade
}

\author{
Chao Wang • Alexey G. Klechikov • Anna L. Gharibyan · Sebastian K. T. S. Wärmländer • \\ Jüri Jarvet $\cdot$ Lina Zhao $\cdot$ Xueen Jia $\cdot$ S. K. Shankar $\cdot$ Anders Olofsson $\cdot$ Thomas Brännström \\ Yuguang Mu $\cdot$ Astrid Gräslund $\cdot$ Ludmilla A. Morozova-Roche
}

Received: 5 July 2013 / Revised: 18 October 2013 / Accepted: 4 November 2013 / Published online: 16 November 2013

(C) The Author(s) 2013. This article is published with open access at Springerlink.com

\begin{abstract}
Pro-inflammatory S100A9 protein is increasingly recognized as an important contributor to inflammation-related neurodegeneration. Here, we provide insights into S100A9 specific mechanisms of action in Alzheimer's disease (AD). Due to its inherent amyloidogenicity S100A9 contributes to amyloid plaque formation together with $\mathrm{A} \beta$. In traumatic brain injury (TBI) S100A9 itself rapidly forms amyloid plaques, which were reactive with oligomerspecific antibodies, but not with $\mathrm{A} \beta$ and amyloid fibrillar antibodies. They may serve as precursor-plaques for $\mathrm{AD}$, implicating TBI as an AD risk factor. S100A9 was observed in some hippocampal and cortical neurons in TBI, AD and non-demented aging. In vitro S100A9 forms neurotoxic linear and annular amyloids resembling $\mathrm{A} \beta$ protofilaments. S100A9 amyloid cytotoxicity and native S100A9 proinflammatory signaling can be mitigated by its co-aggregation with $A \beta$, which results in a variety of micron-scale
\end{abstract}

C. Wang, A.G. Klechikov and A.L. Gharibyan contributed equally.

Electronic supplementary material The online version of this article (doi:10.1007/s00401-013-1208-4) contains supplementary material, which is available to authorized users.

C. Wang · A. G. Klechikov · A. L. Gharibyan · X. Jia ·

A. Olofsson · L. A. Morozova-Roche $(\square)$

Department of Medical Biochemistry and Biophysics, Umeå

University, 90187 Umeå, Sweden

e-mail: ludmilla.morozova-roche@medchem.umu.se

S. K. T. S. Wärmländer · J. Jarvet · A. Gräslund

Department of Biochemistry and Biophysics, Stockholm

University, 10691 Stockholm, Sweden

J. Jarvet

National Institute of Chemical Physics and Biophysics,

Akadeemia tee 23, 12618 Tallinn, Estonia amyloid complexes. NMR and molecular docking demonstrated transient interactions between native S100A9 and $\mathrm{A} \beta$. Thus, abundantly present in AD brain pro-inflammatory S100A9, possessing also intrinsic amyloidogenic properties and ability to modulate $A \beta$ aggregation, can serve as a link between the $\mathrm{AD}$ amyloid and neuroinflammatory cascades and as a prospective therapeutic target.

Keywords A $A$ - Alzheimer's disease - Amyloid . Cytotoxicity $\cdot$ Neuroinflammation $\cdot$ S100A9 $\cdot$ Traumatic brain injury

\section{Introduction}

The amyloid cascade with the leading role of amyloid- $\beta$ $(\mathrm{A} \beta)$ peptides remains a central concept of Alzheimer's disease $(\mathrm{AD})$ pathology. $\mathrm{AD}$ brains contain soluble (neurotoxic oligomers) and insoluble (plaques) assemblies of $\mathrm{A} \beta$, both of which are the focus of intensive research with the aim of using them as targets for potential therapeutic intervention and raising the possibility that their elimination will lead to an $\mathrm{AD}$ cure $[36,44]$. Yet the causes triggering $\mathrm{A} \beta$ aberrant

L. Zhao · Y. Mu

School of Biological Sciences, Nanyang Technological

University, 60 Nanyang Drive, Singapore, Singapore

S. K. Shankar

Human Brain Tissue Repository, Department of Neuropathology,

National Institute of Mental Health and Neurosciences,

Bangalore 560029, India

T. Brännström

Department of Medical Biosciences, Umeå University,

90187 Umeå, Sweden 
accumulation in relatively late age still remain elusive and a second causal event may be required to turn on this pathological cascade. Chronic or acute inflammation, associated for example with traumatic brain injury (TBI), may fulfill this function and currently they are the subject of increasing attention $[3,14]$. The role of inflammation in $\mathrm{AD}$ is supported by a sharp induction of inflammatory mediators in AD-affected brain [25] as well as by epidemiological and experimental studies demonstrating that non-steroidal anti-inflammatory drugs markedly reduce the age-related prevalence of $\mathrm{AD}[7$, 17]. Moreover, these drugs can slow down amyloid deposition by mechanisms that remain still unknown [7]. In this research, we show that the pro-inflammatory protein S100A9 can serve as a critical link between the amyloid cascade and inflammatory events in $\mathrm{AD}$ pathology.

S100A9 acts as a pro-inflammatory mediator and its elevated level was found in many inflammatory conditions, including inflammation-associated AD [37]. A significantly increased microglia expression of S100A9 was observed in the temporal cortex of both familial and sporadic $\mathrm{AD}$ cases compared to old and young controls [37]. In this study S100A9-positive glia was associated with $A \beta$ diffuse deposits and plaques. The Western blot analysis of the brain extracts also revealed a significantly elevated level of S100A9 monomers and high molecular weight complexes in $\mathrm{AD}$ [37], resembling similar dynamics of $\mathrm{A} \beta$ expression in $\mathrm{AD}$ [36]. Therefore, the authors raised the question as whether S100A9 is involved in plaque pathology [37]. Kummer and coauthors [23] observed a significantly increased level of S100A9 (which is denoted also as myeloid-related protein Mrp14 [40]) in the brain lysates and cerebrospinal fluid of $\mathrm{AD}$ patients compared to agematched controls and detected S100A9-positive microglial cells in the vicinity of amyloid plaques - thus all data implicated S100A9 as a neuroinflammatory marker of AD. A widespread expression of S100A9 was reported in the brain in malaria [34], cerebral ischemia [30] and TBI [10], where it may initiate sustainable inflammatory responses and perform cytokine-like functions controlling inflammatory responses of other cells. In an AD mice model S100A9 production was induced by both $\mathrm{A} \beta$ peptide and the $\mathrm{C}$-terminal fragment of the amyloid precursor protein, while S100A9 knockdown attenuated memory impairment and reduced amyloid plaque burden [16]. In AD APP/PS1 mice S100A9 was found to be up-regulated in microglial cells, while the loss of S100A9 by targeted gene disruption led to reduction of the pro-inflammatory cytokine production with dual consequences [23]. Firstly, reduced inflammation decreased the transcription of BACE1 and BACE2, thus limiting the $A \beta$ production and its consequent deposition. Secondly, prevention of excessive microglial activation favored amyloid degradation by microglial phagocytosis, thus acting to protect against AD pathology.
In our previous studies, we have found that the rise of S100A9 level during inflammation may lead to its amyloid formation and deposition in the aging prostate [45] and in the yeast cell model [11]. Both granulocyte extracted and recombinant S100A8/S100A9 complexes formed amyloid oligomers and fibrils also in vitro and the amyloid propensity analysis of S100A8 and S100A9 amino acid sequences revealed that they are intrinsically amyloidogenic [45]. Generally amyloid propensity of S100 protein family was related to their intrinsically disordered sequences, which can be exposed upon loss of structural protection in the native tertiary or quaternary folds and become accessible to amyloid-competent conformations [6]. It has been shown that in vitro the mixture of monomeric and dimeric S100A9 may also induce $A \beta$ fibrillation, suggesting some interactions between S100A9 monomer/dimer and $\mathrm{A} \beta$ aggregates, though these interactions remained elusive [47]. Such interactions ultimately reduced the cytotoxicity attributed in this study to non-aggregated S100A9 [47]. The contacts between S100A9 and short $A \beta(12-24)$ peptide, corresponding to the hydrophobic core of full-length $A \beta$ peptides, were analyzed with an atomic resolution by replica exchange molecular dynamics simulation [48]. It was demonstrated that the hydrogen bonding between S100A9 and the ends of this core $A \beta$ peptide induced $A \beta(12-24)$ straightening and consequently promoted its oligomerization. Interestingly, in vitro amyloid fibrillation was found also to be a property of another protein from S100 familyS100A6, as well as its seeding capacity for superoxide dismutase-1 aggregation, which may be related to the amylotropic lateral sclerosis pathology [4].

It is important to note that recently the abundance of S100A9 mRNA was identified as a strong feature of aging in various mammalian tissues, including the central nervous system, and a novel mechanism of age-associated inflammation sustained by S100A9 was suggested [38]. However, the specific role of S100A9 in AD as well as in aging is still far from clear. Here, by using combined analysis of ex vivo AD-affected brain tissues and modeling S100A9 aggregation and co-aggregation with $A \beta$ in vitro, we demonstrate the direct involvement of S100A9 in AD basic mechanisms from the perspective of its intrinsic amyloidogenicity, ability to form plaques and neurotoxicity, thus bridging the $\mathrm{AD}$ neuroinflammatory and amyloid cascades.

\section{Materials and methods}

Materials

$\mathrm{A} \beta(1-40)$ and $\mathrm{A} \beta(1-42)$ (Alexotech, Sweden) were used in all experiments. Both peptides were dissolved in $10 \mathrm{mM} \mathrm{NaOH}$ to avoid aggregation and then diluted into 
phosphate buffered saline (PBS-140 mM NaCl, $2.7 \mathrm{mM}$ $\mathrm{KCl}, 10 \mathrm{mM} \mathrm{Na} \mathrm{HPO}_{4}$ and $\left.2 \mathrm{mM} \mathrm{KH}_{2} \mathrm{PO}_{4}\right) 10 \mathrm{mM} \mathrm{PBS}$, $\mathrm{pH} 7.4$ to the required final concentration, determined by Bradford assay and by absorbance at $220 \mathrm{~nm} \mathrm{[2].} \mathrm{This}$ preparation method, described in more detail in [42], yields highly uniform and reproducible samples well suited for NMR and other spectroscopic and aggregation studies [12]. S100A9 was expressed in $E$ coli and purified as described previously [41]. Its concentration was determined by using $\varepsilon_{280}=0.53(\mathrm{mg} / \mathrm{ml})^{-1} \mathrm{~cm}^{-1}$.

\section{Tissue samples}

All experimental procedures with tissue samples were approved by the medical ethics committees of the Umea University Hospital, Sweden, and by the Human Brain Tissue Repository for Neurobiological Studies, National Institute of Mental Health and Neurosciences, Bangalore, India. Brain tissues from seven AD patients with the Braak and Braak [5] stages from III to VI, two severe TBI patients of 35 and 51 years, deceased within $72 \mathrm{~h}$ after an accident, and two non-demented control patients - a 75-year-old female, deceased from pulmonary embolism, and a 67-year-old female, deceased from coronary infarction, were examined. All tissues were from the temporal lobe, including the hippocampus, the dentate gyrus, subiculum and also the neocortex. They were paraffin-embedded and microtome-sectioned to $7-\mu \mathrm{m}$-thick slices.

\section{Immunohistochemistry}

Single and sequential immunohistochemistry on the same tissue sections was performed as described previously [15] with some modifications [29]. The following antibodies were used: A $\beta$ (rabbit polyclonal, AS08 328, 1 in 200, Agrisea), S100A9 (rabbit polyclonal, sc-20173, 1 in 100, Santa Cruz Biotechnology), S100B (mouse monoclonal, 9A11B9, 1 in 100, Santa Cruz Biotechnology), phosphorylated-tau (mouse monoclonal, AT8, 1 in 25, Thermo Scientific), fibrillar and A11 (rabbit polyclonal, 1 in 200, gift from Kayed [21]), NeuN (mouse monoclonal, MAB377, 1 in 100, Millipore), GFAP (chicken polyclonal, astrocyte marker ab4674, 1 in 500, Abcam), goat anti-chicken IgY (ab97135, 1 in 2000, Abcam), anti-mouse (MP-7402) and anti-rabbit IgG peroxidase reagent kits (MP-7401), Vector Laboratories. The tissues were scanned by a Pannoramic SCAN slide scanner 250 (3D Histech).

\section{Atomic force microscopy}

Atomic force microscopy (AFM) imaging was carried out by a BioScope Catalyst AFM (Bruker) in peak force mode in air at a resonance frequency of ca. $70 \mathrm{kHz}$ and a resolution of $256 \times 256$ pixels; scan sizes were from 0.5 to $10 \mu \mathrm{m}$. Amyloid samples were deposited on the surface of freshly cleaved mica (Ted Pella) for $15 \mathrm{~min}$, washed $3 \times$ with $100 \mu \mathrm{l}$ deionized water and dried at room temperature.

Fluorescence assays

Thioflavin $\mathrm{T}$ (ThT) and 1-anilinonaphthalene-8-sulfonic acid (ANS) assays were carried out as described previously [45] by using a FP 6500 spectrofluorometer (Jasco) with excitation at 440 and $365 \mathrm{~nm}$ and detecting emission at 485 and $470 \mathrm{~nm}$, respectively; $5 \mathrm{~nm}$ excitation and emission slits were used in both cases.

\section{Cell culture experiments}

SH-SY5Y neuroblastoma cells were cultured with and without amyloids as described previously [20]. Cell viability was measured by WST-1 assay (Roche) after $24 \mathrm{~h}$ co-incubation with amyloids. Absorbance at $450 \mathrm{~nm}$ was measured by a plate reader (Tecan). Cell viability was expressed as a percentage of the absorbance in wells containing treated cells compared to those of control untreated cells. The amyloid samples prepared for cytotoxicity experiments were lyophilised and reconstituted directly prior to adding to the cells in PBS and added to cell culture media at the required concentration. The morphology of amyloid structures was not affected by lyophilisation as examined by AFM imaging.

\section{NMR}

NMR measurements were performed on a Bruker Avance $500 \mathrm{MHz}$ spectrometer equipped with a triple-resonance Bruker CryoProbe including a $z$-axis gradient coil. Diffusion measurements on a $100 \mu \mathrm{M} \mathrm{S100A9}$ sample in $10 \mathrm{mM}$ PBS buffer ( $\left.\mathrm{pH} 7.4 ; 10 / 90 \mathrm{H}_{2} \mathrm{O} / \mathrm{D}_{2} \mathrm{O}\right)$ were carried out at $25{ }^{\circ} \mathrm{C}$ using a bipolar gradient routine (Bruker pulse program ledbpgppr2s, using 32 linearly spaced gradient strengths from 5 to $95 \%$ of maximum strength, with $100 \mathrm{~ms}$ longitudinal storage time and $2 \mathrm{~ms}$ bipolar gradients). The diffusion data for the methyl peak at $0.91 \mathrm{ppm}$ were processed and fitted within the Topspin T1/T2 analysis module. The resulting diffusion coefficient was converted into a corresponding hydrodynamic radius by using the Stokes-Einstein equation. One-dimensional ${ }^{1} \mathrm{H}$ and two-dimensional ${ }^{1} \mathrm{H}_{-}{ }^{15} \mathrm{~N}$ heteronuclear single quantum coherence (HSQC) spectra of $75 \mu \mathrm{M}{ }^{15} \mathrm{~N}$-labeled $\mathrm{A} \beta$ in $10 \mathrm{mM}$ PBS (pH 7.3; 90/10 $\mathrm{H}_{2} \mathrm{O} / \mathrm{D}_{2} \mathrm{O}$ ) were recorded at $25{ }^{\circ} \mathrm{C}$ both before and after addition of $75 \mu \mathrm{M}$ S100A9. The assignment of $\mathrm{A} \beta(1-40)$ amide peaks was performed previously [9]. The weighted average of the ${ }^{1} \mathrm{H}$ and ${ }^{15} \mathrm{~N}$ chemical shift difference $\left(\Delta \delta=\left(0.5\left[\Delta \delta\left({ }^{1} \mathrm{H}\right)^{2}+(0.2 \Delta \delta\right.\right.\right.$ 
$\left.\left.\left.\left({ }^{15} \mathrm{~N}\right)\right)^{2}\right]\right)^{1 / 2}$ ) and the ratio of amide peak intensities measured before and after addition of S100A9 were calculated.

Dynamic light scattering

Samples were analyzed on a Zetasizer Nano (Malvem) DLS instrument by scattered light at $630 \mathrm{~nm}$ and under $173^{\circ}$ angle. $50 \mu \mathrm{M} \mathrm{S100A9}$ in $400 \mu$ l PBS was subjected to five repetitive measurements. Hydrodynamic diameter was evaluated from the autocorrelation curves fitted with the manufacturer's software and molecular weight was calculated by the Protein Utilities program provided by the manufacturer.

\section{Molecular docking}

The S100A9 dimer [18] and $A \beta(1-40)$ monomer [39] were taken as the receptor and ligand, respectively. The Patchdock [35] and Firedock [1] docking programs were applied to find possible binding modes. 17,316 binary models were generated by Patchdock and further optimized by Firedock. 177 binding modes with a docking score lower than -20 were shown.

\section{Results}

S100A9 in plaques in the hippocampal and neocortical areas in $\mathrm{AD}$ and $\mathrm{TBI}$

Sections from the AD hippocampi and neocortical areas of seven patients with the Braak and Braak stages from III to VI were analyzed for the distribution and co-localization of pro-inflammatory and amyloid antigens by using sequential immunohistochemistry as shown in the representative images with a higher magnification in Figs. 1, 2 and in the broader low-magnification views in online supplemental files 1 and 2, respectively. We found that S100A9 is abundantly present throughout the whole hippocampi of AD patients, including amyloid plaques, extensive regions around them and blood vessels (Fig. 1a and supplemental file 1a). By contrast, the staining with $A \beta$ antibodies was localized only in the plaques and blood vessels, but not in the surrounding tissues (Fig. $1 \mathrm{~b}$ and supplemental file $1 \mathrm{~b}$ ). The immunostaining for glial-specific S100B protein was also performed for comparison, as this most studied protein from the S100 family is commonly associated with neurodegenerative disorders and TBI. Interestingly, the staining with S100B antibodies did not overlap with the S100A9 and A $\beta$ patterns: S100B was not detected in plaques and blood vessels, but local staining was observed in tissues surrounding the plaques (Fig. 1c), limited staining was detected around the blood vessel walls and in the white matter of the alveus of hippocampus (supplemental file 1c, low right corner). We have examined the same tissues by immunostaining with GFAP astrocyte-specific antibodies and detected the presence of astrocytes around amyloid plaques. The GFAP-positive pattern showed partial overlap with some local S100B immunostaining (Fig. 1c, d) due to the fact that S100B is produced primarily by mature astrocytes [43]. Staining with anti-amyloid fibrillar antibodies showed a clear correlation with $\mathrm{A} \beta$ and S100A9 depositions within the plaques and blood vessels as shown on the individual and overlapping summary images (Fig. 1e, $\mathrm{k}$ and supplemental file 1d, i).

Similar to the AD hippocampi, the neocortical areas of $\mathrm{AD}$ brains have also shown an abundance of $\mathrm{A} \beta$ and S100A9 amyloid plaques, in which the immunostaining pattern for $\mathrm{A} \beta, \mathrm{S} 100 \mathrm{~A} 9$ and fibrillar antibodies were perfectly overlapped (Fig. 2a, b, e and supplemental file 2). Generally, a higher level of S100A9 expression was found also in the surrounding plaque regions, which were not stained, however, with $\mathrm{A} \beta$ antibodies. The S100B and GFAP staining was observed in the areas neighboring the plaques, but not in the plaques themselves, with partial overlapping (Fig. 2c, d) as indicated above for the AD hippocampi (Fig. 1c, d). We did not observe any noticeable correlation between the distribution of the A $\beta-S 100 A 9$ amyloid plaques in the brain tissues and the Braak and Braak stages (III-VI) of AD. The A $\beta$ and/or S100A9 amyloid plaques were not found in the hippocampi and cortical areas of the two non-demented control patients as shown in the representative immunohistochemical staining images for S100A9 in supplemental files 3a, b.

It is important to note that we have also examined the presence of S100A8 plaques in the AD hippocampi and cortical areas, as S100A8 and S100A9 tend to form heterocomplexes in many but not all tissues [13, 40]. We have not found any S100A8-positive plaques in the CA1, CA3, CA4, dental gyrus and neocortical areas (supplemental files $3 \mathrm{c}-\mathrm{f}$ ), while by contrast we have observed the S100A9positive plaques in all these areas, respectively (supplemental file $3 \mathrm{~g}-\mathrm{j}$ ).

As TBI is viewed as a risk factor and a potential precursor state for $\mathrm{AD}$, the immunohistochemical analysis for the same antigens were performed on two TBI patients, who deceased within $72 \mathrm{~h}$ after the accidents. For both individuals the immunohistochemistry revealed the presence of numerous S100A9 plaques throughout the whole hippocampi (Fig. 3a) as well as their relatively random presence in the neocortical areas close to the hippocampi. By contrast, these plaques were not reactive to antibodies against $\mathrm{A} \beta$, amyloid fibrils and S100B (data not shown), but were stained with A11 anti-amyloid oligomeric antibodies (Fig. 3b). This indicates that S100A9 is not only secreted, but also very rapidly aggregates into amyloid-like plaques in TBI. 



S100A9 in neurons in the hippocampal and neocortical areas in AD and TBI

Apart from the plaques and their surrounding areas, we
4Fig. 1 S100A9 and A $\beta$ plaques in the AD hippocampus. Representative sequential immunohistochemistry of the AD hippocampus tissue with a S100A9, b A $\beta$, c S100B, d GFAP and e fibril-specific antibodies. The corresponding images are shown in pseudo-color: $\mathbf{f}$ S100A9 staining in green; $\mathbf{g} \mathrm{A} \beta$ in yellow; $\mathbf{h} \mathrm{S} 100 \mathrm{~B}$ in blue; $\mathbf{i}$ GFAP in magenta and $\mathbf{j}$ fibrillar in red. $\mathbf{k}$ Superposition of pseudo-color layers. Scale bars are $50 \mu \mathrm{m}$ in all images

observed also distinct positive staining with S100A9 antibodies of neuronal cells in the AD, TBI and control aged brain tissues; all S100A9-positive cells displayed specific neuronal morphology. Figure $3 \mathrm{c}$, e demonstrates a representative immunostaining of pyramidal neurons in the CA3 and neurons in the dentate gyrus regions of one TBI patient and similarly the S100A9-positive neurons were observed throughout the whole TBI hippocampus including also the CA1, CA2 and CA4 areas as well as the neocortex. The neurons in the following tissue slice from the same region were also intensively stained with the NeuN neuron-specific antibodies, verifying that these are indeed neuronal cells (Fig. 3d). The S100A9-positive neurons were also observed in the non-demented control patients; the representative staining of granular neurons in the dentate gyrus is shown in Fig. 3f, though the S100A9-positive neurons were observed also in other areas of the hippocampus and neocortex. In the AD patients the S100A9-positive neurons were abundant in all regions of the hippocampus and neocortex as shown in Fig. $3 \mathrm{~g}$ for the CA4 region and in supplemental file $3 \mathrm{~g}-\mathrm{j}$ for other areas of the hippocampus and neocortex. It is important to note, that some neuronal cells stained with S100A9 antibodies showed also staining with $\mathrm{A} \beta$ antibodies, as demonstrated in the representative images in Fig. $3 \mathrm{~g}$, h, signifying that S100A9 and $\mathrm{A} \beta$ can co-aggregate also within the neuronal cells. By contrast, we have observed an inverse correlation between S100A9 and phosphorylated-tau immunostaining, i.e., neurons intensively stained for S100A9 showed no staining with phosphorylated-tau antibodies (supplemental file 4), indicating that S100A9 is not linked to AD tau-pathology.

\section{Co-aggregation of S100A9 and $A \beta(1-40)$}

The amyloid formation of individual $\mathrm{A} \beta(1-40)$ and S100A9 as well as their mutual effects on each other were examined in vitro in $10 \mathrm{mM}$ PBS, $\mathrm{pH} 7.4,37^{\circ} \mathrm{C}$ under $100 \mathrm{rpm}$ shaking (Fig. 4). It has been reported previously that the theoretical amyloid propensity score of S100A9 is close to the propensity of $A \beta(1-40)$ [45]. Indeed, as assessed by AFM imaging, after $24 \mathrm{~h}$ incubation S100A9 $(50 \mu \mathrm{M})$ aggregated into thin protofilaments, which displayed bead-on-string morphology (Fig. 4a); they were less than $1 \mathrm{~nm}$ in height as measured by AFM cross-section analysis (Fig. 4i). After 3 days incubation these protofilaments developed into very 
Fig. $2 \mathrm{~S} 100 \mathrm{~A} 9$ and $\mathrm{A} \beta$ plaques in the $\mathrm{AD}$ neocortex. Representative sequential immunohistochemistry of the AD neocortical tissue with a S100A9, b A $\beta$, c S100B, d GFAP and e fibril-specific antibodies. The corresponding images are shown in pseudo-color: $\mathbf{f}$ S100A9 staining in green; $\mathbf{g} \mathrm{A} \beta$ in yellow; $\mathbf{h} \mathrm{S} 100 \mathrm{~B}$ in blue; $\mathbf{i}$ GFAP in magenta and $\mathbf{j}$ fibrillar in red. $\mathbf{k}$ Superposition of pseudo-color layers. Scale bars are $50 \mu \mathrm{m}$ in all images

coily, smooth fibrils (Fig. 4b) of ca. $3 \mathrm{~nm}$ height in AFM cross-section and up to a micron length (Fig. 4j). A $\beta(1-40)$ $(20 \mu \mathrm{M})$ also formed thin protofilaments of ca. $1 \mathrm{~nm}$ height with beaded morphology after $24 \mathrm{~h}$ incubation (Fig. 4c and supplemental file 5a). By contrast, in the mixture of S100A9 and $A \beta(1-40)$ (50 and $20 \mu \mathrm{M}$, respectively), the mature amyloid fibrils were fully developed during the same time period with a thickness of $10 \mathrm{~nm}$ and larger and of micron length and longer (Fig. 4d and supplemental file $5 b)$. This clearly demonstrates that S100A9 and A $\beta(1-40)$ drastically enhance each other's amyloidogenicity.

It is important to note that similar fibrils were developed when $A \beta(1-40)(20 \mu \mathrm{M})$ was added to pre-incubated S100A9 $(50 \mu \mathrm{M})$ protofilaments (Fig. 4a) and subjected to further incubation for $24 \mathrm{~h}$ (supplemental files 5c, d). This indicates that preformed amyloid aggregates of S100A9 can serve as templating surfaces for $\mathrm{A} \beta(1-40)$ amyloid assembly.

When S100A9-A $\beta(1-40)$ co-aggregation (20 $\mu \mathrm{M}$ each) was monitored on a longer time scale, the mature fibrils with ca. $10 \mathrm{~nm}$ height were assembled after $24 \mathrm{~h}$ (supplemental files $5 \mathrm{e}, \mathrm{h}$ ), then they developed further into massive fibrillar bundles decorated by globular species after $48 \mathrm{~h}$ (Fig. 4e and supplemental file $5 \mathrm{~g}$ ) and subsequently into super-bundles with ca. $80 \mathrm{~nm}$ height, as measured by AFM cross-section, after $72 \mathrm{~h}$ (Fig. 4f and supplemental file $5 \mathrm{~h})$. With a higher content of S100A9 $(100 \mu \mathrm{M})$ in the S100A9-A $\beta(1-40)$ solution, even larger aggregated clumps were formed on the amyloid scaffolding (supplemental file 5i). We have reported previously that the S100A8/ A9 complexes form super-fibrillar calcified bundles in the aging prostate able to withstand its protease-rich environment [45]. Similarly, S100A9 and A $\beta(1-40)$ can also promote each other's amyloid assembly into joint large supercomplexes. It is important to note, that $A \beta(1-40)$ alone, incubated even at $100 \mu \mathrm{M}$ concentration for $24 \mathrm{~h}$ and up to 7 days, formed mature fibrils but they were still less thick, with ca. $6 \mathrm{~nm}$ height in AFM cross-sections (supplemental files $5 \mathrm{j}, \mathrm{k}$ ), and remained smooth compared to the coated fibrillar bundles of S100A9-A $\beta(1-40)$ discussed above.

A drastically different morphology of S100A9-A $\beta(1-40)$ complexes was observed when their concentration was increased to $100 \mu \mathrm{M}$ each and the shaking rate was raised to $500 \mathrm{rpm}$. Then S100A9-A $\beta(1-40)$ formed highly populated, very regular, rosette-like structures of up to $2 \mu \mathrm{m}$ in


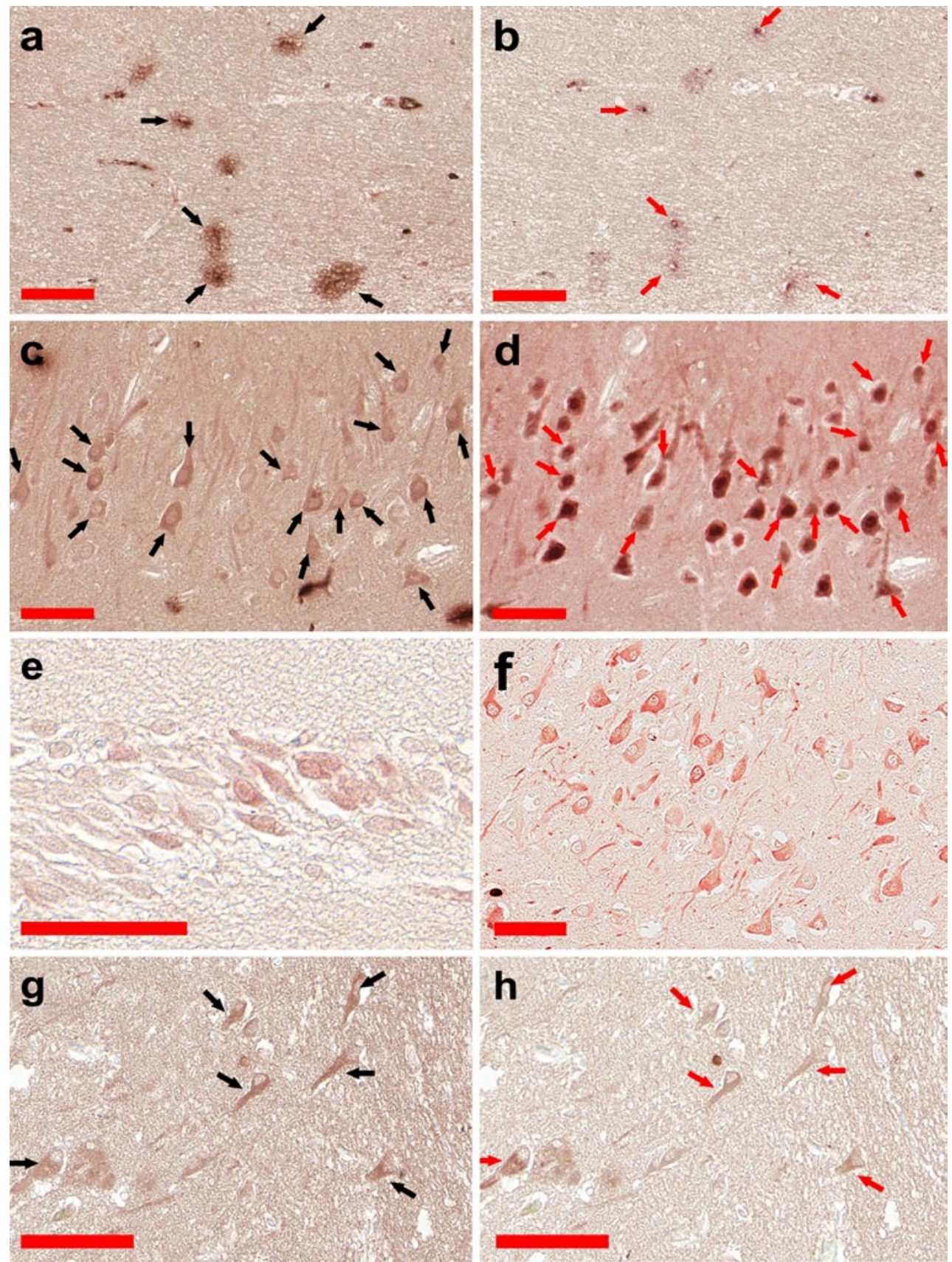

Fig. 3 S100A9 in the TBI hippocampal plaques and in TBI, control and $\mathrm{AD}$ neurons. a Immunohistochemistry of amyloid plaques with S100A9 antibodies and b with A11 oligomer-specific antibodies in the TBI hippocampus. c Staining of hippocampal neurons with S100A9 and d with NeuN neuron-specific antibodies in TBI. e Representative staining of neurons in the TBI and $\mathbf{f}$ the non-demented

diameter and with $10 \mathrm{~nm}$ height in the center (Fig. $4 \mathrm{~g}, \mathrm{~h}$ and supplemental file 5l). This demonstrates that if proteinprotein interactions become more favorable due to higher concentration and higher rate of diffusion, the radial nucleation and growth can kinetically out-compete the linear fibrillar assembly. dentate gyrus with S100A9 antibodies. g Representative sequential staining of pyramidal neurons in the CA4 region in $\mathrm{AD}$ with S100A9 antibodies and $\mathbf{h}$ the same neurons were stained with $A \beta$ antibodies. The same plaques and neurons in sequential tissue sections are indicated by black $(\mathbf{a}, \mathbf{c}, \mathbf{g})$ and red $(\mathbf{b}, \mathbf{d}, \mathbf{h})$ arrows. Scale bars are $100 \mu \mathrm{m}$ in all images

The ThT fluorescence assay, reflecting specific binding of ThT dye to cross- $\beta$-sheet containing amyloids, showed a pronounced increase of ThT fluorescence in all 24-h incubated amyloid samples of S100A9, A $\beta(1-40)$ and S100A9$\mathrm{A} \beta(1-40)$, compared to freshly dissolved polypeptides. The highest ThT fluorescence signal was observed in the 

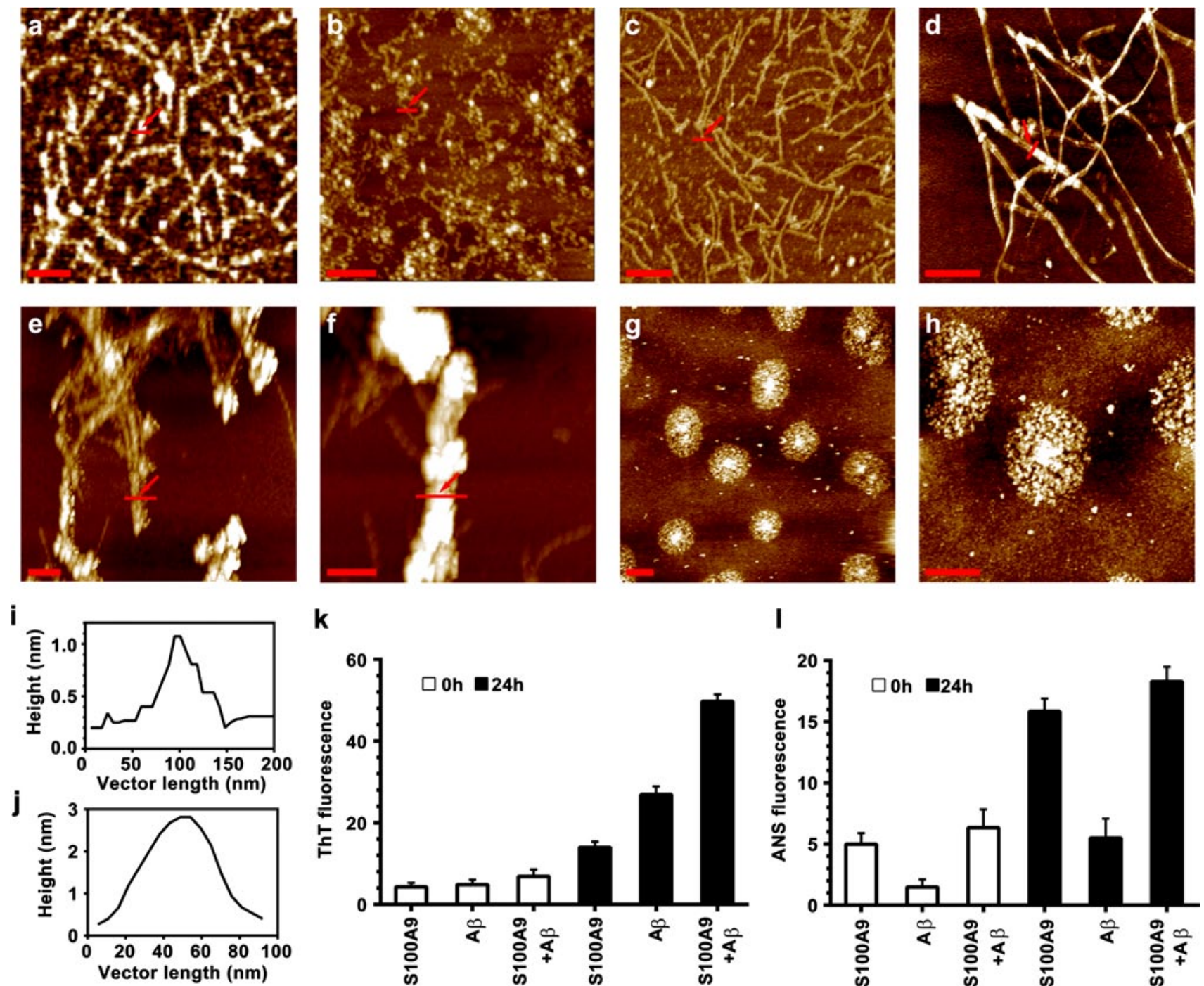

k

I
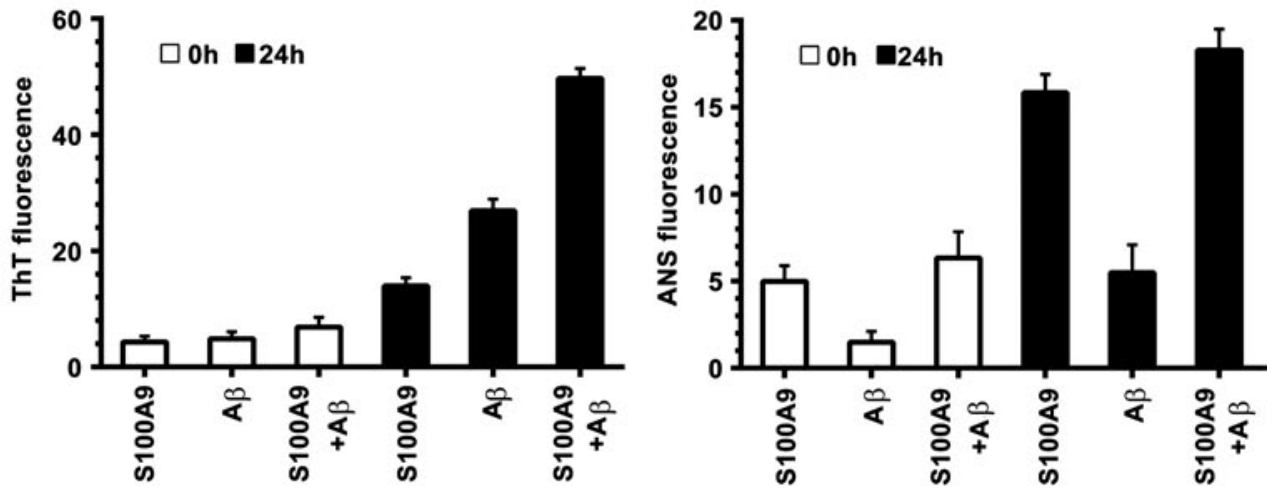

Fig. 4 Co-aggregation of S100A9 and $A \beta(1-40)$. a AFM height images of S100A9 $(50 \mu \mathrm{M})$ protofilaments after $24 \mathrm{~h}$ incubation in $10 \mathrm{mM}$ PBS, $\mathrm{pH} 7.4,37^{\circ} \mathrm{C}$ and with $100 \mathrm{rpm}$ shaking; the same conditions were used in all samples, unless specified. b AFM image of S100A9 fibrils after 5 days incubation; c $\mathrm{A} \beta(1-40)(20 \mu \mathrm{M})$ protofilaments after $24 \mathrm{~h}$; $\mathbf{d}$ fibrils of co-incubated S100A9-A $\beta(1-40)(50$ and $20 \mu \mathrm{M}$, respectively) after $24 \mathrm{~h}$; e coated fibrils of co-incubated S100A9-A $\beta(1-40)$ (both at $20 \mu \mathrm{M}$ ) after $48 \mathrm{~h}$ and $\mathbf{f}$ after $72 \mathrm{~h} ; \mathbf{g}, \mathbf{h}$ the rosettes of co-incubated S100A9-A $\beta(1-40)$ (both at $100 \mu \mathrm{M}$ ) formed after $24 \mathrm{~h}$ upon $500 \mathrm{rpm}$ shaking and shown with different

S100A9-A $\beta(1-40)$ solution reflecting the development of large quantities of mature fibrils (Fig. 4k).

Protein surface hydrophobicity was examined by ANS binding assay monitoring the increase of dye fluorescence upon binding to hydrophobic surfaces (Fig. 41). Both freshly dissolved and amyloid species of S100A9 were characterized by significantly larger hydrophobic surfaces than the respective $A \beta(1-40)$ samples, indicating that in the S100A9-A $\beta(1-40)$ mixture S100A9 may be a major magnification; i AFM cross-section of representative amyloid filament indicated by red arrows in a; f AFM fibrillar cross-section corresponding to $\mathbf{b}$; $\mathbf{k}$ ThT binding assay; $\mathbf{l}$ ANS binding assay. In $\mathbf{k}, \mathbf{l}$ $50 \mu \mathrm{M}$ S100A9 and $20 \mu \mathrm{M} \mathrm{A} \beta(1-40)$ were used; white bars correspond to freshly dissolved polypeptides and black bars to the samples incubated for $24 \mathrm{~h}$. All measurements were referenced to the fluorescence of correspondent free dyes in solution and were taken as an average of five repeats. $x, y$ scale bars are $100 \mathrm{~nm}(\mathbf{a}), 500 \mathrm{~nm}(\mathbf{b}-\mathbf{f})$ and $1 \mu \mathrm{m}(\mathbf{g}, \mathbf{h})$

hydrophobic contributor. This suggests that S100A9 amyloids may provide very effective hydrophobic interfaces significantly promoting the fibrillation of $A \beta(1-40)$.

\section{Cytotoxicity of S100A9 and $A \beta(1-40)$ amyloids}

Since S100A9 is abundant within plaques and hippocampal tissues, we have assessed the cytotoxic damage which S100A9 amyloids can inflict on SH-SY5Y 



Fig. 5 Cytotoxicity of S100A9-A $\beta(1-40)$ amyloids. a Viability of SH-SY5Y neuroblastoma cells measured by WST-1 assay after $24 \mathrm{~h}$ co-incubation with S100A9 amyloids. The viability of untreated cells is taken as $100 \%$. White bars correspond to cells treated with S100A9 linear protofilaments, black bars-with S100A9 annular protofilaments. Bulk S100A9 concentration in $\mu \mathrm{M}$ is shown along $x$-axis. b Viability of SH-SY5Y cells measured by WST-1 assay after 24 h co-incubation with $A \beta(1-40)$ and S100A9-A $\beta(1-40)$ amyloids. Dashed bars correspond to cells treated with $\mathrm{A} \beta(1-40)$ amyloids and grey bars-with co-aggregated S100A9-A $\beta(1-40)$. Grey bar at zero concentration corresponds to the viability in the presence of $20 \mu \mathrm{M}$ S100A9 amyloids as in a. Bulk $\mathrm{A} \beta(1-40)$ concentration in $\mu \mathrm{M}$ is shown along $x$-axis. S100A9 was present at $20 \mu \mathrm{M}$ in all co-incubated S100A9-A $\beta(1-40)$ samples. $* p=0.04, * * p=0.0016$, $* * * p=0.0003$. c AFM height image of S100A9 $(20 \mu \mathrm{M})$ protofilaments assembled in polypropylene tubes and subjected to cytotoxicity assay after $24 \mathrm{~h}$ incubation in $10 \mathrm{mM}$ PBS, $\mathrm{pH} 7.4,37^{\circ} \mathrm{C}$ without shaking; the same incubation conditions were used in other samples. d AFM cross-section of amyloid protofilament indicated by red arrows in $\mathbf{c}$ and $\mathbf{e}$ AFM cross-section corresponding to $\mathbf{f}$ image. $\mathbf{f}$ AFM height image of S100A9 $(20 \mu \mathrm{M})$ rings formed in more hydrophilic polyacrylic tubes; insertion of $80 \times 80 \mathrm{~nm}$ shows an individual S100A9 ring. $g$ AFM height image of $\mathrm{A} \beta(1-40)(20 \mu \mathrm{M})$ protofilaments and $\mathbf{h}$ S100A9-A $\beta(1-40)$ (both at $20 \mu \mathrm{M}$ ) amyloid aggregates. $x, y$ scale bars are $100 \mathrm{~nm}$ in all images

annular protofilaments of S100A9 were produced upon $24 \mathrm{~h}$ incubation in $10 \mathrm{mM}$ PBS, pH 7.4, $37{ }^{\circ} \mathrm{C}$ without shaking (Fig. 5c, d, f). The rings were highly populated upon incubation in less hydrophobic polyacrylic tubes, although they were also present in smaller quantities together with linear protofilaments in four repetitive preparations. They were characterized by ca. $1-1.2 \mathrm{~nm}$ height and ca. $20 \mathrm{~nm}$ diameter measured between highest points on their circumferences in AFM cross-sections (Fig. 5e) and closely resembled amyloid pores of $\mathrm{A} \beta$ and $\alpha$-synuclein reported previously [24]. The A $\beta(1-40)$ amyloid protofilaments (ca. $2 \mathrm{~nm}$ height) and thicker S100A9-A $\beta(1-40)$ fibrils (ca. 4-5 nm height) were produced under the same conditions and are presented in Fig. $5 \mathrm{~g}, \mathrm{~h}$, respectively. As the co-incubation of S100A9 and $A \beta(1-40)$ leads to formation of thicker mature fibrils and potentially even larger aggregates, as we discussed above (Fig. 4), these effectively mitigate the higher cytotoxicity of S100A9 protofilaments (Fig. 5b). 

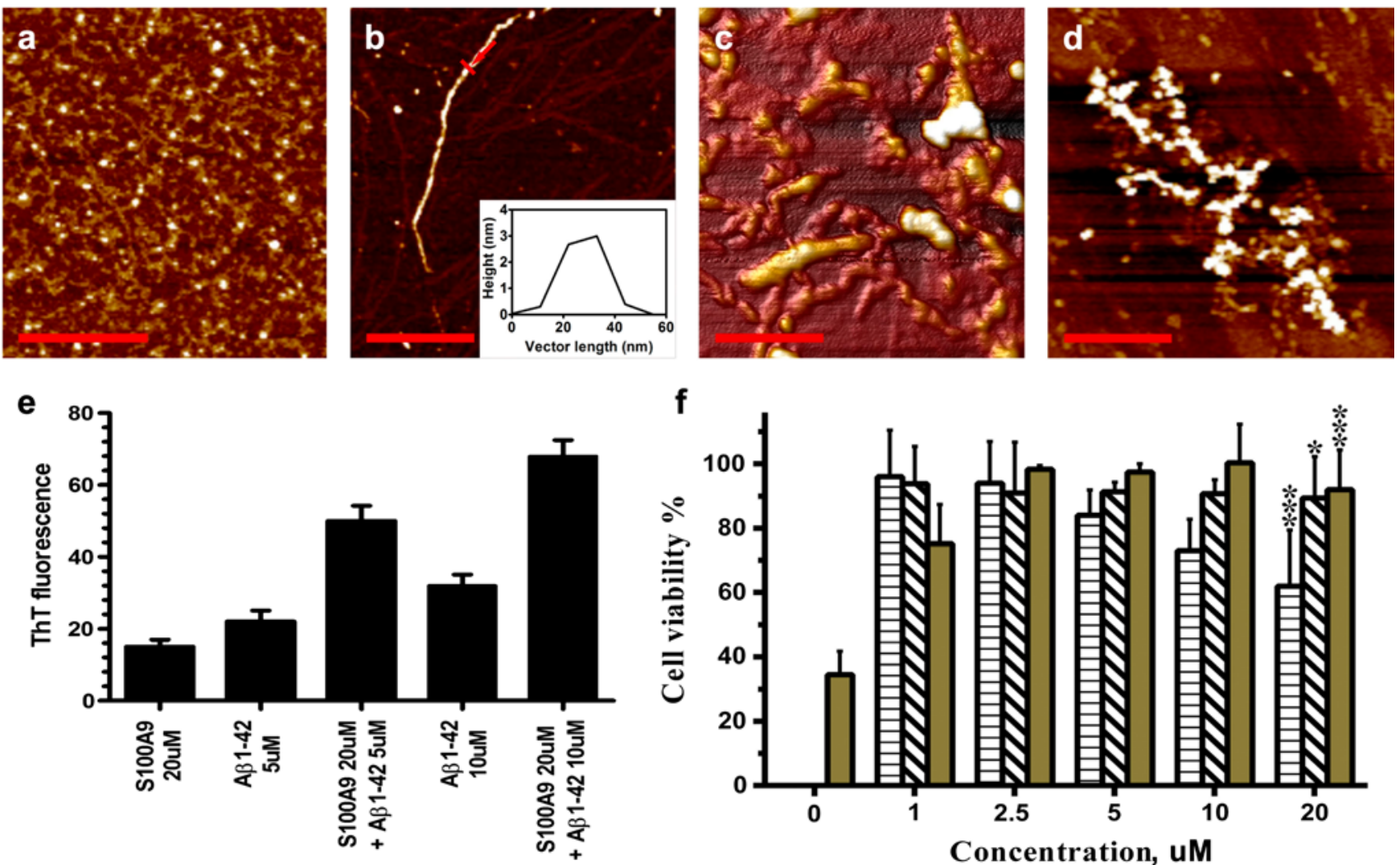

Fig. 6 Co-aggregation and cytotoxicity of S100A9 and $\mathrm{A} \beta(1-42)$ amyloids. a AFM height images of $\mathrm{A} \beta(1-42)(10 \mu \mathrm{M})$ oligomers and protofilaments formed after $7 \mathrm{~h}$ incubation in $10 \mathrm{mM}$ PBS, $\mathrm{pH} 7.4$, $37{ }^{\circ} \mathrm{C}$ without shaking. The same conditions were used in all samples, unless specified. b AFM height image of $A \beta(1-42)(20 \mu \mathrm{M})$ fibril after $24 \mathrm{~h}$ incubation; insertion shows the fibrillar height in the AFM cross-section indicated by red arrow. c AFM 3D image of coaggregated "coated" fibrils of A $\beta(1-42)-S 100 A 9$ (2.5 and $20 \mu \mathrm{M}$, respectively) produced after $24 \mathrm{~h}$. d AFM height images of co-aggregates of $\mathrm{A} \beta(1-42)-\mathrm{S} 100 \mathrm{~A} 9$ (10 and $20 \mu \mathrm{M}$, respectively) persisted after $48 \mathrm{~h}$ co-incubation. e ThT binding assay for 5 and $10 \mu \mathrm{M} \mathrm{A} \beta(1-$ 42) and $20 \mu \mathrm{M} \mathrm{S100A9}$, respectively, incubated for $24 \mathrm{~h}$. All measurements were referenced to the fluorescence of correspondent free

Co-aggregation and cytotoxicity of S100A9 and $\mathrm{A} \beta(1-42)$ amyloids

We have examined also the co-aggregation and gained cytotoxicity of S100A9 and $A \beta(1-42)$ amyloids, since this peptide together with $A \beta(1-40)$ plays a central role in $\mathrm{AD}$ pathogenesis [19]. S100A9 was co-incubated with a range of concentrations of $A \beta(1-42)$ from 1 to $20 \mu \mathrm{M}$ prior subjecting these species to the cytotoxicity experiments. The cytotoxic samples of $\mathrm{A} \beta(1-42)$ developed upon $7 \mathrm{~h}$ incubation in $10 \mathrm{mM}$ PBS, pH 7.4 and $37{ }^{\circ} \mathrm{C}$ were characterized by the presence of oligomers and thin protofilaments with $<1 \mathrm{~nm}$ height as shown in Fig. 6a. Upon longer incubation $A \beta(1-42)$ has developed mature fibrils; a representative image is shown in Fig. $6 \mathrm{~b}$ with a

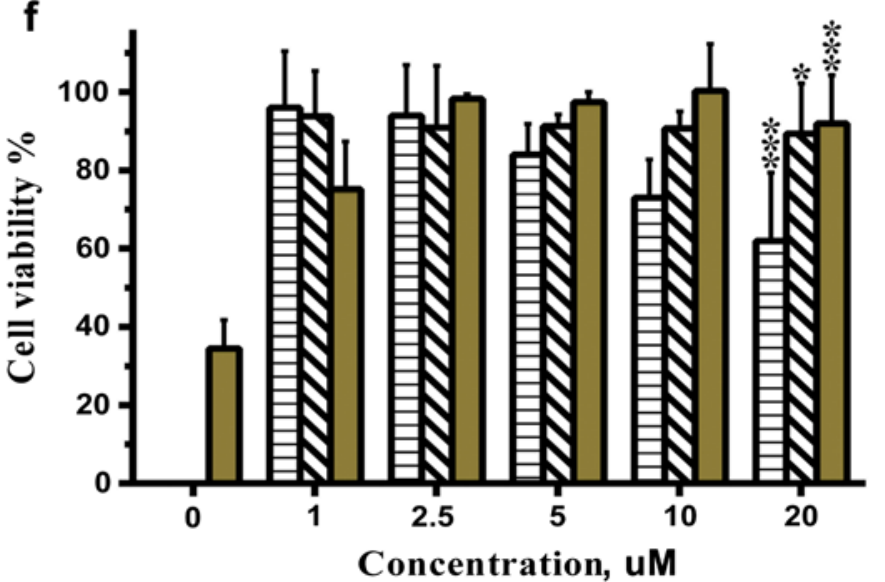

dyes in solution and were taken as an average of three repeats. Specific samples are indicated along $x$-axis. $x, y$ scale bars are $1 \mu \mathrm{m}(\mathbf{a})$, $500 \mathrm{~nm}(\mathbf{b}, \mathbf{d})$ and $200 \mathrm{~nm}(\mathbf{c})$. f Viability of SH-SY5Y neuroblastoma cells measured by WST- 1 assay after $24 \mathrm{~h}$ co-incubation with $\mathrm{A} \beta(1-$ 42) and S100A9 amyloids. The viability of untreated cells is taken as $100 \%$. Bulk $\mathrm{A} \beta(1-42)$ concentration in $\mu \mathrm{M}$ is shown along $x$-axis. S100A9 was at $20 \mu \mathrm{M}$ in all experiments. Olive bars correspond to cells treated with co-aggregated $\mathrm{A} \beta(1-42)-\mathrm{S} 100 \mathrm{~A} 9$; bars with horizontal stripe pattern - to cells treated with $\mathrm{A} \beta(1-42)$ oligomers and protofilaments formed after $7 \mathrm{~h}$ (Fig. 6a); bars with diagonal stripe pattern-to cells treated with $\mathrm{A} \beta(1-42)$ mature fibrils formed after $24 \mathrm{~h}(\mathbf{b}) . * p=0.026, * * * p=0.0003$

height in the AFM cross-section of ca. $3 \mathrm{~nm}$. By contrast, co-incubation of even $2.5 \mu \mathrm{M} \mathrm{A \beta}(1-42)$ with $20 \mu \mathrm{M}$ S100A9 led to the formation of much thicker coated fibrils with the variable height in the AFM cross-section from 4-5 to 10-13 nm (Fig. 6c). The same type of coated fibrillar aggregates was observed upon co-incubation of higher concentrations of $A \beta(1-42)$ with S100A9 and persisted on a longer time scale as shown in the representative image of co-aggregation of $10 \mu \mathrm{M} \mathrm{A} \beta(1-42)$ with $20 \mu$ M S100A9 after $48 \mathrm{~h}$ (Fig. 6d). Similar to the co-aggregation of S100A9 with $\mathrm{A} \beta(1-40)$, the complexes of $A \beta(1-42)$ and S100A9 produced at 1:4 and 1:2 molar ratios showed significantly higher ThT signal compared to the individual components incubated during the same period of $24 \mathrm{~h}$ (Fig. 6e). 
Fig. 7 Interaction of native S100A9 and $A \beta(1-40)$ examined by NMR. a NMR diffusion of S100A9 measured at $25^{\circ} \mathrm{C}$. Methyl peak intensities at $0.91 \mathrm{ppm}$ in a.u. are shown as a function of gradient field strength $G, \mathrm{~cm}^{-1}$. b $1 \mathrm{D}^{1} \mathrm{H}$ NMR spectrum of S100A9. c $2 \mathrm{D}{ }^{1} \mathrm{H}-{ }^{15} \mathrm{~N}$ HSQC spectra of $\mathrm{A} \beta(1-40)$ prior (blue) and after (red) addition of S100A9. d Differences in $A \beta(1-40)$ chemical shifts induced by S100A9 binding versus $A \beta(1-40)$ amino acid residue numbers. e Ratios of $A \beta(1-40)$ amide peak intensities measured in the presence $(I)$ and in the absence $\left(I_{\mathrm{o}}\right)$ of S100A9 versus $A \beta(1-40)$ amino acid residue numbers
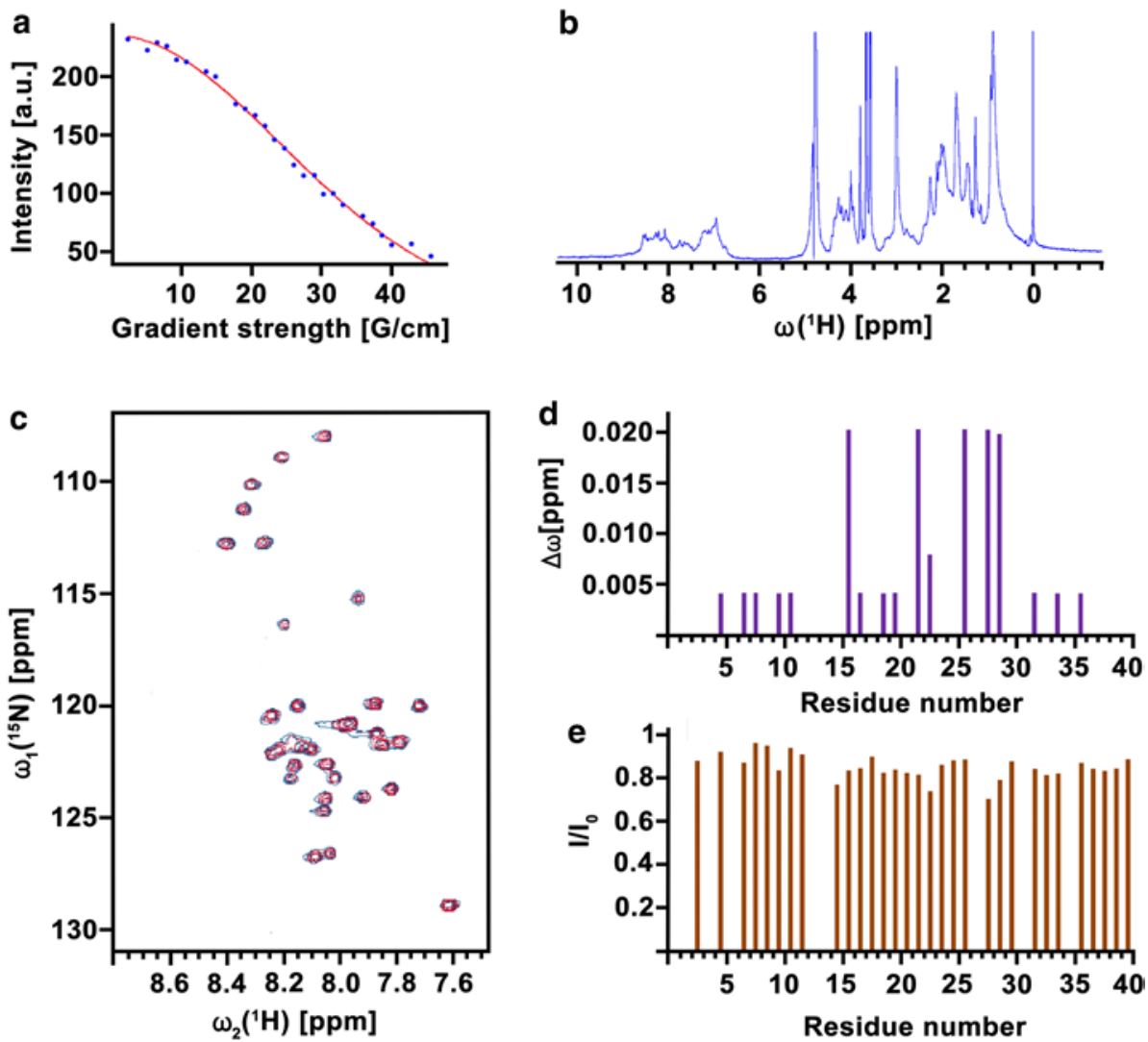

The measurements of the SH-SY5Y cell line viability in the presence of oligomers and protofilaments of $A \beta(1-42)$ showed decrease by up to ca. $40 \%$ upon increasing amyloid concentrations (Fig. 6a, f), while the fibrils of $A \beta(1-$ 42) were not toxic (Fig. 6b, f). This is consistent with the previously published results [19]. It is interesting to note, that co-aggregation of S100A9 with $A \beta(1-42)$ leading to the formation of thick coated aggregates resulted in the complete elimination of the $A \beta(1-42)$ and S100A9 amyloid cytotoxicity already at $1: 8$ molar ratio of $A \beta(1-42)$ and S100A9 (Fig. 6f). This is a significantly more pronounced mitigating effect on S100A9 amyloid cytotoxicity than in the case of co-aggregation of $A \beta(1-40)$ and S100A9, as then even at 1:1 molar ratio the cell viability remained $30 \%$ lower compared to controls (Fig. 5b).

Interactions of native S100A9 and $A \beta$

The interactions of native S100A9 and $A \beta(1-40)$ (selected as a representative $A \beta$ peptide) were analyzed by using solution NMR and molecular docking. The initial state of S100A9 was evaluated by using NMR diffusion (Fig. 7a) and dynamic light scattering (not shown), which both consistently demonstrated that this is a dimer with a molecular weight of ca. $27 \mathrm{kDa}$ and hydrodynamic radius of ca. $3 \mathrm{~nm}$, respectively. The latter indicated also that ca. $1 \%$ of protein is present in aggregated state. The broad NMR signals in $1 \mathrm{D}{ }^{1} \mathrm{H}$ NMR spectrum of native S100A9 suggest that there is a chemical exchange and dynamic equilibrium between the monomeric and dimeric forms (Fig. 7b).

$2 \mathrm{D}{ }^{1} \mathrm{H}^{-15} \mathrm{~N}$ HSQC spectra of $75 \mu \mathrm{M} \mathrm{A} \beta(1-40)$ were recorded before and after addition of S100A9. The spectra reflect an essentially monomeric and unstructured form of A $\beta(1-40)$ [42]. Small chemical shifts (ca. $0.015 \mathrm{ppm}$ ) for residues K16, E22, S26, K28, G29, together with a 20 $30 \%$ decrease in peak intensity for some central $\mathrm{A} \beta(1-40)$ residues (e.g., K28), indicate a possible transient binding site in this central region (Fig. 7c-e).

The analysis of interactions between S100A9 dimer and $A \beta(1-40)$ monomer by molecular docking is shown in Fig. 8a. A total of 177 binding modes of $A \beta(1-40)$ were superimposed on the S100A9 dimer, which were selected based on their docking scores lower than -20 . The corresponding binding interfaces involve the two faces of S100A9 dimer, each composed of helix I and helix III' (helix III' from the other protomer). Structural clustering analysis for these 177 binding modes with a cutoff of $0.2 \mathrm{~nm}$ showed that there are 118 clusters with the largest cluster consisting of 12 members. The multiple clustering without dominant clusters indicates that the binding between S100A9 dimer and $A \beta(1-40)$ has a diffusive character as opposed to specific docking. The S100A9 residues, 
Fig. 8 Molecular interactions of S100A9 and A $\beta$ peptides and their role in $\mathrm{AD}$. a Molecular docking of S100A9 dimer and $\mathrm{A} \beta(1-40)$ monomer. Backbones of S100A9 dimer and $\mathrm{A} \beta(1-40)$ are shown in red ribbons and green beads, respectively. 177 best ranked binding modes of $\mathrm{A} \beta(1-40)$ are superimposed. Upper and lower panels show the side and top views, respectively. Helices I and III as binding candidates are indicated. b Schematic summary of multiple amyloid pathways of S100A9, A $\beta$ peptides and co-aggregated S100A9-A $\beta$. The aggregated structures of individual polypeptides are outlined in red; in co-aggregated complexes S100A9 is schematically denoted in yellow and $\mathrm{A} \beta$-in blue. $\mathbf{c}$ Schematic outline of the role of S100A9 in $\mathrm{AD}$ amyloid-neuroinflammatory cascade. Soluble $\mathrm{A} \beta$ peptides (shown in blue) and S100A9 (in yellow) secreted by neurons and activated microglia (A-Mi) are toxic to neurites and synapses. They accumulate into senile amyloid plaques, which recruit microglial cells. Microglia is further activated by S100A9 via the TLR 4 and RAGE signaling pathways. Level of S100A9 rises, leading to its further amyloid deposition. The cycle is completed as shown by green arrows

such as $\mathrm{H}_{2} \mathrm{O}$ from helix I, D30 from the linker between helices I and II and R85 and L86 from helix III, were found to make particularly close contacts with $A \beta(1-40)$. On the $\mathrm{A} \beta(1-40)$, residues $\mathrm{H} 14, \mathrm{~F} 20$ and $\mathrm{K} 28$ from the middle and V39 and V40 from the C-terminus are primary candidates for the interaction with S100A9. This is consistent with NMR results, where $2 \mathrm{D}{ }^{1} \mathrm{H}^{-}{ }^{15} \mathrm{~N}-\mathrm{HSQC}$ measurements showed that S100A9 interactions induce chemical shift changes and reduced signal intensities in central $\mathrm{A} \beta(1-40)$ residues, particularly K28 (Fig. 7c-e). Both S100A9 and $\mathrm{A} \beta(1-40)$ interfaces and in particular S100A9 helices I and III include significant clustering of positive and negative charges as well as aromatic amino acid residues. Therefore, transient interactions between S100A9 and A $\beta(1-40)$ may include electrostatic component, guiding them towards each other, and hydrophobic binding, providing the interface for $A \beta(1-40)$ molecules diffusion and self-assembly into amyloid structures.

\section{Discussion}

Pro-inflammatory mediator S100A9 was identified as potential contributor to $\mathrm{AD}$ development in patients [23, 37] and mice models [16] and to inflammation-dependent aging in the human body [38]. The understanding of S100A9 mechanisms of action is still at a very early stage and this knowledge is critical as S100A9 can serve both as a risk factor and therapeutic target in $\mathrm{AD}$ diagnostics and treatment. Indeed, regularly administered general antiinflammatory drugs, used to treat concomitant diseases, produce also a positive effect on $\mathrm{AD}$, slowing down its progression [7, 26]. Here, we have shown that S100A9 is highly abundant in AD brain (Figs. 1, 2 and supplemental files 1-3), and due to its inherent amyloidogenicity it can play a key role in AD development. Specifically, S100A9
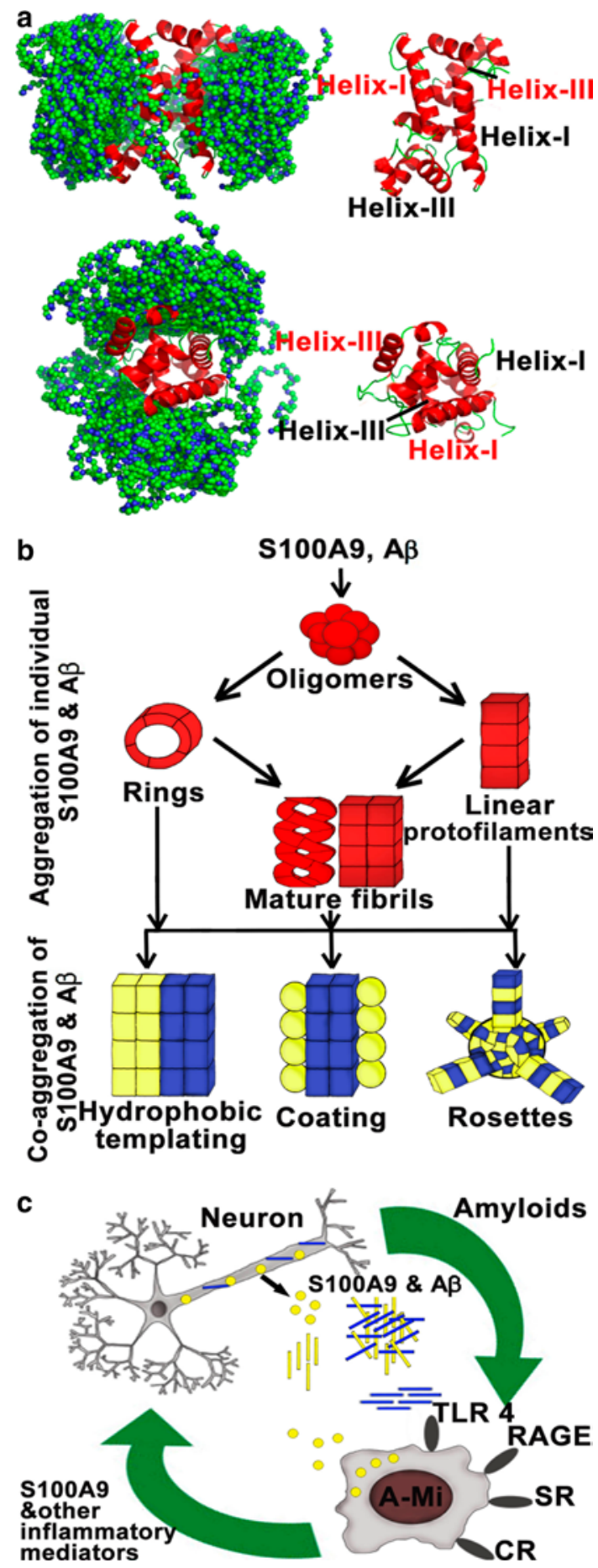

can be a trigger and an important contributor to plaque formation and neurotoxicity. Immunohistochemical analysis demonstrated that together with $\mathrm{A} \beta$ peptide S100A9, but not another well-known brain inflammatory protein $\mathrm{S} 100 \mathrm{~B}$, is consistently present in the $\mathrm{AD}$ plaques and amyloid deposits in the blood vessel walls, forming co-aggregates reactive with anti-fibrillar antibodies. S100A9 is also abundant in tissues surrounding amyloid deposits (Figs. 1, 2 and 
supplemental files 1-2), indicating that an elevated level of S100A9 can favor its aggregation and deposition.

Remarkably, in TBI hippocampi the numerous plaques that rapidly developed within less than $72 \mathrm{~h}$ post-accident were composed of S100A9 on its own, but not with $A \beta$. These plaques were reactive with A11 amyloid oligomer antibodies, indicating that already within this short time period S100A9 has undergone amyloid-type conformational changes (Fig. 3a, b). It is important to note that apart from catastrophic brain injuries, head traumas are common in various sports and have received increasing attention due to their neuropathological consequences and similarities with $\mathrm{AD}$ [3]. TBI is considered also as a potential risk condition for $\mathrm{AD}$ development. In AD pathology the amyloid cascade is a central hypothesis and amyloid plaques are a major pathological hallmark of disease, respectively, with the chief role in these phenomena designated to $A \beta$. We have demonstrated here that highly amyloidogenic S100A9 is able to form amyloid structures in vitro just as rapidly as $\mathrm{A} \beta$ (Figs. 4, 5). S100A9 and its amyloids are also more hydrophobic than $\mathrm{A} \beta$ (Fig. 4l) and if the plaques fulfill the function of a sink for various toxic species and cell debris not cleared by cellular machineries, S100A9 is a perfect candidate for the role of plaque-forming protein, able to sequestrate all these materials on its sticky hydrophobic surfaces. S100A9 also readily co-aggregates with both $A \beta(1-40)$ and $A \beta(1-42)$ and promotes their amyloid deposition (Figs. 4, 5, 6). Therefore, the amyloid plaques of S100A9 rapidly developed in TBI brain, in fact, can serve as the precursors of $\mathrm{AD}$ amyloid plaques, linking TBI and $A D$ via the amyloid cascade mechanism.

S100A9 is secreted by macrophages and the activated microglia in inflammation-associated $\mathrm{AD}$ can produce a significantly elevated level of S100A9, which can locally exceed the $A \beta$ level. The initial form of S100A9 is primarily homodimers as we have shown by NMR diffusion experiments and dynamic light scattering, though the broad lines in 1D NMR spectrum indicate that there is an equilibrium exchange between monomers and dimers. However, S100A9 does not stay in its native state for long and within hours or days under close to physiological conditions in vitro (pH 7.4 and $37{ }^{\circ} \mathrm{C}$ ) it forms a plethora of amyloid complexes, including linear and annular amyloid protofilaments and flexible fibrils (Figs. 4, 5). Remarkably, S100A9 protofilaments and especially its annular species closely resemble similar amyloid structures of leading amyloid polypeptides such as $\mathrm{A} \beta$ and $\alpha$-synuclein in $\mathrm{AD}$ and Parkinson's disease, respectively (Fig. 5, [24]) and they are also cytotoxic towards SH-SY5Y neuroblastoma cells (Fig. 5). However, the toxicity of S100A9 amyloids subsides if S100A9 is pre-incubated with an increasing concentration of $A \beta(1-40)$ and is completely eliminated during coincubation with $A \beta(1-42)$, starting from their molar ration of 1:8 for $A \beta(1-42)$ and S100A9, respectively. This occurs due to their co-aggregation into larger aggregated species and $\mathrm{A} \beta(1-42)$ apparently is more potent in this regard than $\mathrm{A} \beta(1-40)$ (Figs. 5, 6). Native freshly dissolved S100A9 by itself also showed some cellular toxicity (ca. $18 \%$ ), but due to its progressing aggregation under the conditions of experiment, this toxicity may be related to its aggregates.

Even larger plethora of amyloid species were formed when S100A9 and $A \beta(1-40)$ or $A \beta(1-42)$ were co-aggregated together as shown in Figs. 4, 5, 6 and schematically summarized in Fig. 8b. Since amyloid formation is a concentration-dependent as well as a thermodynamically and kinetically controlled process [28], depending on the concentration ratio of S100A9 and $A \beta$, one of them can be prompted to aggregate into thermodynamically stable aggregates faster than the other. Here, we consider a few possible scenarios depending on the concentrations of both counterparts and conditions of amyloid formation, such as shaking, which may facilitate protein-protein interactions. As we have shown above, the amyloid fibrils of S100A9$\mathrm{A} \beta(1-40)$ (taken at 50 and $20 \mu \mathrm{M}$, respectively) displayed smooth surfaces and were significantly thicker and longer than the fibrils of individual counterparts formed even on a longer time scale and also at higher respective polypeptide concentration (Fig. 4d and supplemental file 5b). Importantly, similar smooth and thick fibrils were produced when preformed S100A9 amyloid protofilaments (Fig. 4a) were added in solution as templates for the $\mathrm{A} \beta$ fibrillation (supplemental files $5 \mathrm{c}, \mathrm{d})$. Thus, if one of the counterparts is prompted to aggregate faster, for example the more hydrophobic S100A9, it can provide a hydrophobic templating surface for $\mathrm{A} \beta$ assembly.

When we mixed S100A9 and $A \beta(1-40)$ at $1: 1$ ratio and $20 \mu \mathrm{M}$ each, instead of smooth fibrils, we have observed polymers coated with round-shaped aggregates and the thickness of the coat drastically increased upon $72 \mathrm{~h}$ incubation, reaching $80 \mathrm{~nm}$ (Fig. $4 \mathrm{f}$ and supplemental file $5 \mathrm{~h}$ ). It is most likely that an $\mathrm{A} \beta(1-40)$ fibrillar surface may attract S100A9 coatings, if the former aggregates faster at these concentrations of both counterparts. Similar coating interactions were observed also when S100A9 was co-incubated with $A \beta(1-42)$ (Fig. 6c, d).

Remarkably, when we increased the concentration of both S100A9 and $A \beta(1-40)$ to $100 \mu \mathrm{M}$ and also introduced vigorous shaking, new rosette-type regular co-aggregates were produced (Fig. $5 \mathrm{~g}$ ). The rosettes were highly populated and constituted the dominant amyloid species in the sample; they reached up to $2 \mu \mathrm{m}$ in diameter and displayed a regular radial pattern of co-aggregation. This may reflect the fact that the protein binding process is too rapid to be kinetically controlled at more aggregation-prone conditions, thus the radial growth will out-compete the more slow linear assembly. Undoubtedly, all these new types of co-aggregated 
structures require further structural investigation. Here, our task was to demonstrate their heterogeneity and the possibility of refining their properties by varying incubation conditions. It should be also considered that in the affected tissues the massive and rapid co-aggregation can be a lesser evil as this can effectively remove from circulations more toxic and damaging species. We have shown this above by reducing and eliminating S100A9 amyloid toxicity during its coaggregation with increasing concentrations of $A \beta(1-40)$ and $A \beta(1-42)$, respectively (Figs. 5b, 6f).

Interestingly, by NMR and molecular docking we observed transient or diffusive interactions between S100A9 dimer and $\mathrm{A} \beta$ monomer, but not their specific docking into each other's surface (Fig. 6a), which would also cause a significant perturbation in the ${ }^{1} \mathrm{H}-{ }^{15} \mathrm{~N}$ HSQC spectrum of $A \beta$ (Fig. 5). S100A9 surface hydrophobicity and clustering of charged residues, particularly in helices I and III, provide, most likely, the interface for $\mathrm{A} \beta$ own selfassembly, rather than promoting strong binding between $\mathrm{A} \beta$ and S100A9. The opposite, e.g., S100A9 self-assembly on $A \beta$ interface, may also take place as we discussed above, depending on the initial conditions and concentrations of both counterparts. Diffusive motility of microtubule and DNA binding proteins may provide an insightful analogue for the nature of the diffusive interactions [8]. The strong specific binding may ultimately lead to inhibition of amyloid formation rather than its promotion as these polypeptides have very different non-complementary amino acid sequences to be integrated within the same cross- $\beta$ sheet [22].

Importantly, we have observed also consistent immunostaining of hippocampal neurons with S100A9 antibodies in AD, TBI and non-demented aging, indicating that S100A9 can be also produced by neuronal cells. In some neuronal cells S100A9 was co-localized with $A \beta$, indicating that their co-aggregation can occur intracellularly (Fig. 3g, h). By contrast, intracellular S100A9 is not colocalized with hypo-phosphorylated tau as it was examined by sequential immunostaining of the same tissues (supplemental file 4), indicating that S100A9 may not be associated with tau-pathology, which is another key feature of AD. It is interesting to note, that overexpression of S100A8 and S100A9 was observed in neurons of Kras mutant mice model acting as an early trigger of gliosis. In the mutant mice cortex the neuronal S100A8/A9 expression pattern was clearly associated with increased infiltration by microglia [32]. It is not excluded that similar events can be also implicated in the inflammatory cascades in AD and TBI. Inflammation clearly occurs in pathologically vulnerable regions of $\mathrm{AD}$ brain, but the mediators and mechanisms playing a key role in this process remained as yet obscure. Here, we have demonstrated that S100A9 can act as a link between the amyloid and inflammatory cascades (Fig. 8c).
Indeed, during $\mathrm{AD}$ plaque formation microglia become activated and recruited to the plaque deposition sites [31], causing microgliosis. The activated microglia secretes S100A9 as well as an array of other pro- and anti-inflammatory mediators. This can contribute to changes in neuronal calcium homeostasis [27] and accelerate neuritic and synaptic dysfunction [46]. As a result, S100A9 expression in neuronal cells can be also turned on, which further activates microglia via the toll-like receptor 4 (TLR 4) and receptor for advanced glycation end products (RAGE) signaling pathways $[32,33]$. A significantly raised level of extracellular S100A9 promotes its amyloid aggregations and also co-aggregation with $A \beta$. Protofilaments of S100A9 itself are highly neurotoxic (Fig. 5a) and are able to inflict rapid damage and death to neurons. As the co-aggregation of S100A9 with $A \beta(1-40)$ or $A \beta(1-42)$ proceeds more efficiently than for individual counterparts, the co-aggregation process may act as an emergency sink, rapidly removing from circulation the neurotoxic amyloid species of both polypeptides as well as native S100A9 able to act as TLR 4 and RAGE activator. The ultimate price for this "rescue" clearance process, however, can be the exacerbated growth of the amyloid plaques in $\mathrm{AD}$ brain. It is known from our previous studies that the amyloid complexes of S100A9 are much more stable and protease resistant compared to amyloids of other proteins [45] and their clearance and removal may be therapeutically unachievable. Furthermore, the plaques themselves may exacerbate microglia activation, thus completing the vicious circle of amyloid-neuroinflammatory cascade (Fig. 8c).

Due to its amyloidogenicity, neurotoxicity and signaling functions, S100A9 may be a promising therapeutic target. Bearing in mind its multifaceted nature, the most effective way would be to target in the first instance its overexpression and secretion rather than deal with subsequent clearance of its multiple native and amyloid species, especially as the latter can be extremely stable and resistant to any interventions. Detailed studies of the effect of non-steroidal anti-inflammatory drugs on S100A9 system, which have already proved to be useful in slowing $\mathrm{AD}$, may hold the key to effective $\mathrm{AD}$ treatment.

Acknowledgments We are deeply grateful to Rakez Kayed for a gift of A11 and fibrillar antibodies. We thank Thomas Höckenström for usage of an Aperio scanscope and Maria Johansson, Kristoffer Brännström and Ulla-Stina Spetz for invaluable technical help. L. A. M-R., T. B. and A. G. acknowledge support from the Swedish Medical Research Council, and L. A. M-R. from the Insamlingsstiftelsen and the Kempe foundation. A. G. K. thanks the Swedish Institute for his fellowship. S. W. received funding from the Magnus Bergvall Foundation. Y. Mu thanks the support of the IDA Cloud Computing Call, NTU Tier 1 grant RG 23/11, Nanyang Analytics NTU HPC Cluster and the A*STAR Computational Resource Centre (http://www.acrc.astar.edu.sg) for the use of its high performance computing facilities. 
Conflict of interest The authors declare that they have no conflicting interests.

Open Access This article is distributed under the terms of the Creative Commons Attribution License which permits any use, distribution, and reproduction in any medium, provided the original author(s) and the source are credited.

\section{References}

1. Andrusier N, Nussinov R, Wolfson HJ (2007) FireDock: fast interaction refinement in molecular docking. Proteins 69(1):139159. doi:10.1002/prot.21495

2. Bhaskar K, Miller M, Chludzinski A, Herrup K, Zagorski M, Lamb BT (2009) The PI3K-Akt-mTOR pathway regulates Abeta oligomer induced neuronal cell cycle events. Mol Neurodegener 4:14. doi:10.1186/1750-1326-4-14

3. Blennow K, Hardy J, Zetterberg H (2012) The neuropathology and neurobiology of traumatic brain injury. Neuron 76(5):886899. doi:10.1016/j.neuron.2012.11.021

4. Botelho HM, Leal SS, Cardoso I, Yanamandra K, MorozovaRoche LA, Fritz G, Gomes CM (2012) S100A6 amyloid fibril formation is calcium-modulated and enhances superoxide dismutase-1 (SOD1) aggregation. J Biol Chem 287(50):4223342242. doi:10.1074/jbc.M112.396416

5. Braak H, Braak E (1991) Neuropathological stageing of Alzheimer-related changes. Acta Neuropathol 82(4):239-259

6. Carvalho SB, Botelho HM, Leal SS, Cardoso I, Fritz G, Gomes CM (2013) Intrinsically disordered and aggregation prone regions underlie beta-aggregation in S100 proteins. PLoS One 8(10):e76629. doi:10.1371/journal.pone.0076629

7. Cole GM, Frautschy SA (2010) Mechanisms of action of non-steroidal anti-inflammatory drugs for the prevention of Alzheimer's disease. CNS Neurol Disord Drug Targets 9(2):140-148

8. Cooper JR, Wordeman L (2009) The diffusive interaction of microtubule binding proteins. Curr Opin Cell Biol 21(1):68-73. doi:10.1016/j.ceb.2009.01.005

9. Danielsson J, Andersson A, Jarvet J, Gräslund A (2006) 15 N relaxation study of the amyloid beta-peptide: structural propensities and persistence length. Magn Reson Chem 44 Spec No:S114-S121. doi:10.1002/mrc.1814

10. Engel S, Schluesener H, Mittelbronn M, Seid K, Adjodah D, Wehner HD, Meyermann R (2000) Dynamics of microglial activation after human traumatic brain injury are revealed by delayed expression of macrophage-related proteins MRP8 and MRP14. Acta Neuropathol 100(3):313-322

11. Eremenko E, Ben-Zvi A, Morozova-Roche LA, Raveh D (2013) Aggregation of human S100A8 and S100A9 amyloidogenic proteins perturbs proteostasis in a yeast model. PLoS One 8(3):e58218. doi:10.1371/journal.pone.0058218

12. Fezoui Y, Hartley DM, Harper JD, Khurana R, Walsh DM, Condron MM, Selkoe DJ, Lansbury PT Jr, Fink AL, Teplow DB (2000) An improved method of preparing the amyloid beta-protein for fibrillogenesis and neurotoxicity experiments. Amyloid 7(3):166-178

13. Fritz G, Botelho HM, Morozova-Roche LA, Gomes CM (2010) Natural and amyloid self-assembly of S100 proteins: structural basis of functional diversity. FEBS J 277(22):4578-4590. doi:10.1111/j.1742-4658.2010.07887.x

14. Gandy S, Heppner FL (2013) Microglia as dynamic and essential components of the amyloid hypothesis. Neuron 78(4):575-577. doi:10.1016/j.neuron.2013.05.007

15. Glass G, Papin JA, Mandell JW (2009) SIMPLE: a sequential immunoperoxidase labeling and erasing method. J Histochem Cytochem 57(10):899-905. doi:10.1369/jhc.2009.953612
16. Ha TY, Chang KA, Kim J, Kim HS, Kim S, Chong YH, Suh YH (2010) S100a9 knockdown decreases the memory impairment and the neuropathology in Tg2576 mice, AD animal model. PloS One 5(1):e8840. doi:10.1371/journal.pone.0008840

17. in t' Veld BA, Ruitenberg A, Hofman A, Launer LJ, van Duijn CM, Stijnen T, Breteler MM, Stricker BH (2001) Nonsteroidal antiinflammatory drugs and the risk of Alzheimer's disease. N Engl J Med 345(21):1515-1521. doi:10.1056/NEJMoa010178

18. Itou H, Yao M, Fujita I, Watanabe N, Suzuki M, Nishihira J, Tanaka I (2002) The crystal structure of human MRP14 (S100A9), a $\mathrm{Ca}(2+)$-dependent regulator protein in inflammatory process. $\mathrm{J}$ Mol Biol 316(2):265-276. doi:10.1006/jmbi.2001.5340

19. Jan A, Lashuel HA (2012) Establishing the links between $\mathrm{Ab}$ aggregation and cytotoxicity in vitro using biophysical approaches. In: Sigurdsson EM (ed) Amyloid proteins: methods and protocols, 2nd edn. Springer, New York, pp 227-243

20. Jia X, Gharibyan AL, Ohman A, Liu Y, Olofsson A, MorozovaRoche LA (2011) Neuroprotective and nootropic drug noopept rescues alpha-synuclein amyloid cytotoxicity. J Mol Biol 414(5):699-712. doi:10.1016/j.jmb.2011.09.044

21. Kayed R, Head E, Sarsoza F, Saing T, Cotman CW, Necula M, Margol L, Wu J, Breydo L, Thompson JL, Rasool S, Gurlo T, Butler P, Glabe CG (2007) Fibril specific, conformation dependent antibodies recognize a generic epitope common to amyloid fibrils and fibrillar oligomers that is absent in prefibrillar oligomers. Mol Neurodegener 2:18. doi:10.1186/1750-1326-2-18

22. Krebs MR, Morozova-Roche LA, Daniel K, Robinson CV, Dobson CM (2004) Observation of sequence specificity in the seeding of protein amyloid fibrils. Protein Sci 13(7):1933-1938. doi:10.1110/ps.04707004

23. Kummer MP, Vogl T, Axt D, Griep A, Vieira-Saecker A, Jessen F, Gelpi E, Roth J, Heneka MT (2012) Mrp14 deficiency ameliorates amyloid beta burden by increasing microglial phagocytosis and modulation of amyloid precursor protein processing. J Neurosci 32(49):17824-17829. doi:10.1523/JNEUROSCI.1504-12.2012

24. Lashuel HA, Hartley D, Petre BM, Walz T, Lansbury PT Jr (2002) Neurodegenerative disease: amyloid pores from pathogenic mutations. Nature 418(6895):291. doi:10.1038/418291a

25. McGeer EG, McGeer PL (2010) Neuroinflammation in Alzheimer's disease and mild cognitive impairment: a field in its infancy. J Alzheimer's Dis 19(1):355-361. doi:10.3233/ JAD-2010-1219

26. McGeer PL, Schulzer M, McGeer EG (1996) Arthritis and antiinflammatory agents as possible protective factors for Alzheimer's disease: a review of 17 epidemiologic studies. Neurology 47(2):425-432

27. Park KM, Yule DI, Bowers WJ (2008) Tumor necrosis factoralpha potentiates intraneuronal $\mathrm{Ca} 2+$ signaling via regulation of the inositol 1,4,5-trisphosphate receptor. J Biol Chem 283(48):33069-33079. doi:10.1074/jbc.M802209200

28. Pellarin R, Schuetz P, Guarnera E, Caflisch A (2010) Amyloid fibril polymorphism is under kinetic control. J Am Chem Soc 132(42):14960-14970. doi:10.1021/ja106044u

29. Pirici D, Mogoanta L, Kumar-Singh S, Pirici I, Margaritescu C, Simionescu C, Stanescu R (2009) Antibody elution method for multiple immunohistochemistry on primary antibodies raised in the same species and of the same subtype. J Histochem Cytochem 57(6):567-575. doi:10.1369/jhc.2009.953240

30. Postler E, Lehr A, Schluesener H, Meyermann R (1997) Expression of the S-100 proteins MRP-8 and -14 in ischemic brain lesions. Glia 19(1):27-34

31. Rogers J, Lue LF (2001) Microglial chemotaxis, activation, and phagocytosis of amyloid beta-peptide as linked phenomena in Alzheimer's disease. Neurochem Int 39(5-6):333-340

32. Ryu MJ, Liu Y, Zhong X, Du J, Peterson N, Kong G, Li H, Wang J, Salamat S, Chang Q, Zhang J (2012) Oncogenic Kras 
expression in postmitotic neurons leads to S100A8-S100A9 protein overexpression and gliosis. J Biol Chem 287(27):2294822958. doi:10.1074/jbc.M112.357772

33. Schlachetzki JC, Hull M (2009) Microglial activation in Alzheimer's disease. Curr Alzheimer Res 6(6):554-563

34. Schluesener HJ, Kremsner PG, Meyermann R (1998) Widespread expression of MRP8 and MRP14 in human cerebral malaria by microglial cells. Acta Neuropathol 96(6):575-580

35. Schneidman-Duhovny D, Inbar Y, Nussinov R, Wolfson HJ (2005) PatchDock and SymmDock: servers for rigid and symmetric docking. Nucleic Acids Res 33(Web Server issue):W363W367. doi:10.1093/nar/gki481

36. Selkoe DJ (2000) Toward a comprehensive theory for Alzheimer's disease. Hypothesis: Alzheimer's disease is caused by the cerebral accumulation and cytotoxicity of amyloid beta-protein. Ann NY Acad Sci 924:17-25

37. Shepherd CE, Goyette J, Utter V, Rahimi F, Yang Z, Geczy CL, Halliday GM (2006) Inflammatory S100A9 and S100A12 proteins in Alzheimer's disease. Neurobiol Aging 27(11):1554-1563. doi:10.1016/j.neurobiolaging.2005.09.033

38. Swindell WR, Johnston A, Xing X, Little A, Robichaud P, Voorhees JJ, Fisher G, Gudjonsson JE (2013) Robust shifts in S100a9 expression with aging: a novel mechanism for chronic inflammation. Sci Rep 3:1215. doi:10.1038/srep01215

39. Vivekanandan S, Brender JR, Lee SY, Ramamoorthy A (2011) A partially folded structure of amyloid-beta(1-40) in an aqueous environment. Biochem Biophys Res Commun 411(2):312-316. doi:10.1016/j.bbrc.2011.06.133

40. Vogl T, Gharibyan AL, Morozova-Roche LA (2012) Proinflammatory S100A8 and S100A9 proteins: Self-assembly into multifunctional native and amyloid complexes. Int J Mol Sci 13(3):2893-2917. doi:10.3390/ijms13032893

41. Vogl T, Leukert N, Barczyk K, Strupat K, Roth J (2006) Biophysical characterization of S100A8 and S100A9 in the absence and presence of bivalent cations. Biochim Biophys Acta 1763(11):1298-1306. doi:10.1016/j.bbamcr.2006.08.028

42. Wählstrom A, Hugonin L, Peralvarez-Marin A, Jarvet J, Gräslund A (2008) Secondary structure conversions of Alzheimer's Abeta(1-40) peptide induced by membrane-mimicking detergents. FEBS J 275(20):5117-5128. doi:10.1111/j.1742-4658.2008.06643.x

43. Wang DD, Bordey A (2008) The astrocyte odyssey. Prog Neurobiol 86(4):342-367. doi:10.1016/j.pneurobio.2008.09.015

44. Wärmlander S, Tiiman A, Abelein A, Luo J, Jarvet J, Söderberg KL, Danielsson J, Gräslund A (2013) Biophysical studies of the amyloid beta-peptide: interactions with metal ions and small molecules. Chembiochem 14(14):1692-1704. doi:10.1002/c bic. 201300262

45. Yanamandra K, Alexeyev O, Zamotin V, Srivastava V, Shchukarev A, Brorsson AC, Tartaglia GG, Vogl T, Kayed R, Wingsle G, Olsson J, Dobson CM, Bergh A, Elgh F, Morozova-Roche LA (2009) Amyloid formation by the pro-inflammatory S100A8/A9 proteins in the ageing prostate. PLoS One 4(5):e5562. doi:10.1371/ journal.pone.0005562

46. Yoshiyama Y, Higuchi M, Zhang B, Huang SM, Iwata N, Saido TC, Maeda J, Suhara T, Trojanowski JQ, Lee VM (2007) Synapse loss and microglial activation precede tangles in a P301S tauopathy mouse model. Neuron 53(3):337-351. doi:10.1016/j. neuron.2007.01.010

47. Zhang C, Liu Y, Gilthorpe J, van der Maarel JR (2012) MRP14 (S100A9) protein interacts with Alzheimer beta-amyloid peptide and induces its fibrillization. PLoS One 7(3):e32953. doi:10.1371/journal.pone.0032953

48. Zhao LN, Zhang T, Zhang C, Wang C, Morozova-Roche LA, Chew LY, Mu Y (2013) S100A9 induces aggregation-prone conformation in $\mathrm{A} \beta$ peptides: A combined experimental and simulation study. RSC Adv. doi:10.1039/C3RA43665A 